Tropical Journal of Pharmaceutical Research December 2010; 9 (6): 595-603

(C) Pharmacotherapy Group, Faculty of Pharmacy, University of Benin

Benin City, 300001 Nigeria.

All rights reserved.

Review Article

Available online at http://www.tjpr.org

\title{
Arformoterol Tartrate: A Review of Pharmacology, Analysis and Clinical Studies
}

\author{
Rakesh Pahwa ${ }^{1 *}$, Vijay Soni ${ }^{1}$, Prabodh Chander Sharma ${ }^{1}$, Vipin \\ Kumar $^{1}$ and Kanchan Kohli ${ }^{2}$ \\ ${ }^{1}$ Institute of Pharmaceutical Sciences, Kurukshetra University, Kurukshetra-136119, India. ${ }^{2}$ Faculty of Pharmacy, \\ Hamdard University, New Delhi-110062, India
}

\begin{abstract}
This article is a review of the therapeutic significance of arformoterol tartrate, a new generation $\beta_{2}$ adrenergic agonist bronchodilator available in a nebulized form. Arformoterol is well absorbed through the lungs when administered via a standard jet nebulizer and is useful in long-term maintenance therapy of bronchoconstriction in chronic obstructive pulmonary disease (COPD). Much clinical evidence suggest the potentially enhanced efficacy of this drug in the treatment of COPD including chronic bronchitis and emphysema. Various hyphenated analytical methodologies have also been employed for the determination and quantification of arformoterol. This review provides an updated account on the pharmacology, pharmacokinetics, clinical studies, analytical techniques, drug-drug interactions, contraindications, and therapeutic applications of arformoterol tartrate.
\end{abstract}

Keywords: Arformoterol tartrate, Adrenergic agonist, Bronchodilator, COPD. 


\section{INTRODUCTION}

Global Initiative for Chronic Obstructive Lung Disease (GOLD) has defined chronic obstructive pulmonary disease (COPD) as a disease state characterized by airflow limitation that is not fully reversible. It is a progressive ailment generally associated with chronic reduced airflow, breathing difficulty, and pathologic pulmonary changes. It includes emphysema, an anatomically defined condition characterized by destruction and enlargement of the lung alveoli; chronic bronchitis which is a condition with chronic or recurrent excessive mucus secretion; and small airways disease, a condition in which small bronchioles are narrowed [1-4]. The characteristic symptoms of COPD are chronic and progressive dyspnea, cough, and sputum production. Chronic cough and sputum production may precede the development of airflow limitation. COPD is also characterized by various pathologic changes in proximal airways, peripheral airways, lung parenchyma, and pulmonary vasculature [5].

Most of the information available on COPD prevalence, morbidity and mortality comes from developed countries [6]. In 2000, over 119,000 deaths in the United States and 2.74 million deaths worldwide were attributed to COPD. Data from the National Health Interview Survey in 2001 indicates that 12.1 million people over age 25 years in the United States had COPD. Over 9 million of these individuals had chronic bronchitis; the others had emphysema or a combination of both diseases [4]. A study conducted by the Global Burden of Disease under the auspices of the World Health Organization (WHO) and the World Bank concluded that the worldwide prevalence of COPD in 1990 was $9.34 / 1,000$ and $7.33 / 1,000$ in men and women, respectively. The prevalence of this disease is highest in those countries where cigarette smoking is very common [6]. This disease accounted for 8 million medical outpatient visits, 1.5 million visits to emergency departments, and over 700,000 hospitalizations in the year 2000 [7].

COPD is the fourth leading cause of death in the United States, exceeded only by cancer, heart disease and cerebrovascular accidents, accounting for 120,816 deaths in 2002 [4,7]. In the European Union, respiratory diseases accounted for a total direct cost of about $6 \%$ of the total healthcare budget, with $56 \%$ (€38.6 billion) of this expenditure due to COPD [5]. The reported physician-diagnosed COPD prevalence is approximately 10 million people in United States but nearly 24 million persons may have COPD as indicated by self-reporting surveys. Compared to other common chronic diseases, the prevalence of COPD has steadily increased during the past 30 years and it is estimated that by the year 2020 , it will become the third leading cause of death worldwide. In 2004, the economic impact of COPD was estimated at US\$37.2 billion, including over US\$16 billion in indirect morbidity and mortality costs [4,7]. COPD was ranked sixth as the cause of death in 1990 by the study projected by Global Burden of Disease [5].

A variety of factors appear to increase the risk of developing COPD. These include asthma, air pollution, respiratory infections, chemicals, prenatal or childhood illness, nutrition and certain occupational dusts; of these, cigarette smoking remains the most important. Several investigation techniques for COPD includes the application of chest Xray, spirometry, helium dilution technique and computed tomography which allow the detection, characterization and diagnosis of this disease [8]. Table 1 summarizes the various stages of COPD severity.

Inflammation of the airway wall is also associated with asthma. Increased number of various types of inflammatory cells, most notably eosinophils but also basophils, mast cells, macrophages, and certain types of lymphocytes, may be observed in airway walls [9]. 
Table 1: Various stages of COPD severity $[1,2]$

\begin{tabular}{|c|c|c|c|c|c|}
\hline Stage & Stage 0 & Stage I & Stage II & Stage III & Stage IV \\
\hline Severity & At risk & Mild & Moderate & Severe & Very severe \\
\hline Symptoms & $\begin{array}{l}\text { Chronic } \\
\text { cough, } \\
\text { sputum } \\
\text { production }\end{array}$ & $\begin{array}{l}\text { With or } \\
\text { without } \\
\text { chronic } \\
\text { cough or } \\
\text { sputum } \\
\text { production } \\
\quad \leq 0.7\end{array}$ & $\begin{array}{l}\text { With or } \\
\text { without } \\
\text { chronic } \\
\text { cough or } \\
\text { sputum } \\
\text { production } \\
\quad \leq 0.7\end{array}$ & $\begin{array}{l}\text { With or } \\
\text { without } \\
\text { chronic } \\
\text { cough or } \\
\text { sputum } \\
\text { production } \\
\quad \leq 0.7\end{array}$ & $\begin{array}{l}\text { With or } \\
\text { without } \\
\text { chronic } \\
\text { cough or } \\
\text { sputum } \\
\text { production } \\
\quad \leq 0.7\end{array}$ \\
\hline $\begin{array}{l}\mathrm{FEV}_{1} \text { (\% of } \\
\text { predicted } \\
\text { value) }\end{array}$ & $\geq 80$ & $\geq 80$ & $50-80$ & $30-50$ & $<30$ \\
\hline
\end{tabular}

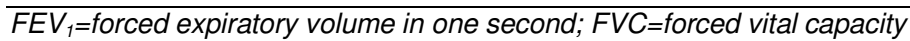

\section{BRONCHODILATORS}

Among the various therapeutic agents currently available for COPD, the focus of treatment is primarily on bronchodilators. Within this class, inhaled therapy is generally preferred over systemic therapy due to improved efficacy and favorable safety margins for additive benefits along with reduced side effects. Several options, including short- and long-acting inhaled $\beta$ agonists, short and long acting inhaled anticholinergics, and methylxanthines exist for the treatment of COPD. Short-acting bronchodilators may be used for patients with mild disease but long-acting bronchodilators are more appropriate for patients with moderate to severe conditions. In general, $\beta_{2^{-}}$ agonists are in the broader class of sympathomimetic agents, which include agents that stimulate $\alpha, \beta_{1}$, and $\beta_{2}$ receptors $[7,8]$. Compounds that are $\beta_{2}$ selective are widely used to provide acute relief from airways obstruction in patients with asthma. Currently available $\beta_{2}$ selective therapies are classified depending on the duration of action. These include albuterol, levalbuterol, pirbuterol, and terbutaline which act as shortacting agents while long-acting agents include formoterol and salmeterol. However, the bronchoprotection afforded by short- acting drugs persist for less than $3-4 \mathrm{~h}$, so that it becomes necessary to use these drugs regularly to achieve symptomatic control. $\beta_{2}$ selective agonists with a longer duration of action have been introduced into therapy $[7,10]$.

\section{Arformoterol}

Arformoterol (R,R-formoterol) is a active isomer of racemic formoterol and is indicated for the long-term, maintenance treatment of bronchoconstriction in patients with COPD including chronic bronchitis and emphysema. It is a new generation long-acting $\beta_{2}$ adrenergic agonist (LABA) bronchodilator for the treatment of COPD and is administered twice daily in the nebulized form. It is a potent and selective agent which causes bronchial smooth muscle relaxation and inhibits the release of inflammatory mediators. Arformoterol tartrate inhalation solution is a sterile, clear, colourless solution of the tartrate salt of arformoterol, the $(R, R)$ enantiomer of formoterol. The chemical structure of arformoterol tartrate is depicted in Figure 1. The molecular weight of this drug is $494.5 \mathrm{~g} / \mathrm{mol}$. It is a white to off white solid powder, slightly soluble in water $[11,12]$. 


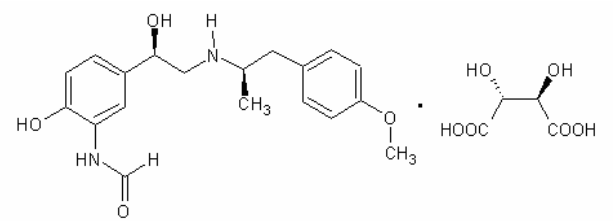

Fig. 1: Structure of arformoterol tartrate

\section{Pharmacology}

Arformoterol is a potent, selective, $\beta_{2}$ adrenergic agonist and long acting bronchodilator which acts in a way similar to that of other $\beta_{2}$ adrenergic agonists such as formoterol and salmeterol. Its pharmacological effects can be attributed to the increased intracellular cyclic adenosine monophosphate (cAMP) levels that result from the stimulation of intracellular adenyl cyclase. Increased intracellular cAMP level causes relaxation of bronchial smooth muscles and inhibits the release of mediators of immediate hypersensitivity from cells, especially mast cells [12].

\section{Pharmacokinetics}

Arformoterol tartrate is well absorbed through lungs when administered by a nebulizer. The mean peak plasma concentration $\left(\mathrm{C}_{\max }\right)$ and systemic exposure $\left(\mathrm{AUC}_{0-12 \mathrm{~h}}\right)$ are $4.3 \mathrm{pg} / \mathrm{mL}$ and $34.5 \mathrm{pg} . \mathrm{h} / \mathrm{mL}$, respectively, when $15 \mu \mathrm{g}$ arformoterol is administered every $12 \mathrm{~h}$ for 14 days in COPD patients. The time to achieve median steady state peak plasma concentration $\left(t_{\max }\right)$ is approximately half an hour after drug administration. The mean terminal half-life is $26 \mathrm{~h}$ in COPD patients when treated with $15 \mu \mathrm{g}$ inhaled arformoterol twice daily for 14 days. The binding of arformoterol to human plasma proteins in vitro is $52-65 \%$ at concentrations of $0.25,0.5$ and $1.0 \mathrm{ng} / \mathrm{mL}$ of radiolabeled arformoterol. Metabolism occurs primarily by direct conjugation (glucuronidation) and secondary route of metabolism is via O-demethylation. Metabolism is mediated by atleast five human uridine diphosphoglucuronosyltransferase (UGT) isozymes as well as CYP2D6 and CYP2C19. After administration of a single oral dose of radiolabeled arformoterol, $63 \%$ of the radioactive amount was recovered in urine and $11 \%$ in feces within $48 \mathrm{~h}$. A total of $89 \%$ of the total radioactive dose was recovered within 14 days, with $67 \%$ in urine and $22 \%$ in faeces [11].

\section{Clinical studies}

Several clinical studies have been conducted with arformoterol tartrate to determine its pharmacokinetics and/or pharmacodynamics efficacy. Baumgartner et al conducted clinical trials on 717 patients with COPD using arformoterol tartrate and salmeterol xinafoate versus placebo in a 12-week, multicenter, double-blind, double-dummy and randomized study. All patients, including male and female (aged $\geq 35$ years), with physician-diagnosed COPD received arformoterol $(15 \mu \mathrm{g}$ bid, 25 $\mu \mathrm{g}$ bid, or $50 \mu \mathrm{g}$ qid via nebulizer), salmeterol (42 $\mu \mathrm{g}$ bid via metered-dose inhaler, MDI), or placebo. In the study, patients with moderate to severe COPD treated with nebulized arformoterol were observed to have significant and sustained improvement in airways functions and dyspnea compared to placebo [13].

Tashkin et al conducted a clinical study which was designed to evaluate the safety and efficacy of concomitant treatment with nebulized arformoterol $15 \mu \mathrm{\mu g}$ bid and tiotropium $18 \mu \mathrm{g}$ qid dry powder inhaler (DPI) in the treatment of COPD. It was a 2-week, prospective, multicenter, randomized, modified-blind, and double dummy, parallel group study. The results demonstrated mean $\mathrm{FEV}_{1} \mathrm{AUC}_{0-24 \mathrm{~h}}$ improvement from baseline for arformoterol $(0.10 \mathrm{~L})$ and tiotropium $(0.08 \mathrm{~L})$ treatment groups and greater for the combined therapy $(0.22 \mathrm{~L})$. Peak $F E V_{1}$, peak FVC and dyspnea were also improved in mono-therapies and greatest with combined therapy [14].

Donohue et al performed an open-label, multicenter, 52-week trial to predict the effects of nebulized arformoterol and salmeterol MDI on COPD patients using short 
acting bronchodilators. Participants were randomized to nebulized arformoterol $50 \mu \mathrm{g}$ dose once daily or salmeterol $42 \mu \mathrm{g}$ dose twice per day. Decrease in albuterol and ipratromium use were observed in both treatment groups, and remained stable over 52 weeks. COPD exacerbation frequency also did not increase over time [15].

Kharidia et al conducted a pharmacokinetic/ pharmacodynamic study comparing nebulized arformoterol $15 \mu \mathrm{g}$ and racemic formoterol DPI (12 and $24 \mu \mathrm{g}$ ) in subjects with COPD. It was an open-label, two-week randomized, multicenter, multi-dose, threeway crossover study conducted on 39 subjects who received study medication twice daily, among whom 33 subjects (84.6\%) received all treatments and completed the trial. In this study, steady-state exposure to $(\mathrm{R}, \mathrm{R})$-formoterol in COPD subjects was similar following 14 days of administration of either $15 \mu \mathrm{g}$ nebulized arformoterol or $12 \mu \mathrm{g}$ of racemic formoterol DPI and lower than that with $24 \mu \mathrm{g}$ racemic formoterol DPI [16].

Hanrahan et al also performed a doubleblind, 12-week, randomized trial to determine the effect of nebulized arformoterol on airway function in patients with COPD. Pulmonary function efficacy of nebulized arformoterol (15 $\mu \mathrm{g}$ bid, $25 \mu \mathrm{g}$ bid, $50 \mu \mathrm{g}$ qid) and salmeterol MDI (42 $\mu \mathrm{g}$ bid) versus placebo was assessed in 1456 subjects. The percent change in trough $\mathrm{FEV}_{1}$, percent change in $F E V_{1}$ average $A U C_{0-12 h}$ and peak percent change in $\mathrm{FEV}_{1}$ from pre-dose were analyzed. The results demonstrated that improvement in trough $\mathrm{FEV}_{1}$ over 12 weeks was greater for arformoterol and salmeterol versus placebo. Increase in $\mathrm{FEV}_{1} \mathrm{AUC}_{0-12 \mathrm{~h}}$ and peak percent change was also greater for arformoterol than for salmeterol. After 12 weeks study, $78-87 \%$ of arformoterol subjects had $\geq 10 \%$ increase in $\mathrm{FEV}_{1}$ from pre-dose (56\% salmeterol, $44 \%$ placebo). Trials demonstrated a significant and sustained improvement in lung function over 12 weeks with COPD subjects on nebulized arformoterol [17]. In the same year, the authors also undertook two double-blind, randomized clinical trials to describe the pretreatment arrhythmia occurrence frequency in patients with COPD and to determine the effects of inhaled long-acting $\beta_{2}$-agonists such as arformoterol and salmeterol. In this study, $24 \mathrm{~h}$ Holter monitoring data were pooled from two identically designed phase III trials. The patients were randomized to LABA treatment or placebo for 12 weeks: a) nebulized arformoterol $15 \mu \mathrm{g}$ bid; b) $25 \mu \mathrm{g}$ bid; or c) 50 $\mu \mathrm{g}$ qid; d) salmeterol metered dose inhaler 42 $\mu \mathrm{g}$ bid; or e) placebo. Proportions of occurrence of various types of arrhythmias such as atrial tachycardia, atrial fibrillation/flutter, and nonsustained and sustained ventricular tachycardia were observed. The results demonstrated that atrial tachycardia occurred more frequently $(41.8 \%)$ than atrial fibrillation/flutter $(0.1 \%)$, nonsustained ventricular tachycardia $(3.1 \%)$, and $>10$ beat ventricular tachycardia $(0.3 \%)$ [18].

Lotvall et al, in a randomized double-blind crossover study, examined the effect of formoterol racemate and enantiomers on bronchodilation in 46 patients with reversible asthma. Formoterol was inhaled by nebulizer $(4.5$ and $36 \mu \mathrm{g})$ as the racemate, (2.25 and $18 \mu \mathrm{g})$ of $(\mathrm{R}, \mathrm{R})$-formoterol, $18 \mu \mathrm{g}$ of $(\mathrm{S}, \mathrm{S})$ formoterol or placebo. Airway and systemic effects were assessed by serial measurement of forced expiratory volume $\left(F E V_{1}\right)$ and heart rate. The results demonstrated that racemate and $(R, R)$ formoterol significantly and dose-dependently increased $F E V_{1}$ and no significant effects were observed for $(\mathrm{S}, \mathrm{S})$-formoterol on $\mathrm{FEV}_{1}$ and heart rate [19].

These clinical studies indicate that arformoterol tartrate provides significant and sustained improvement in airways functions of patients suffering from moderate to severe COPD with fewer side effects and better tolerance. These studies also indicate that this drug can be a promising candidate for COPD therapy and may be administered in 
nebulized form with sustained duration of action.

\section{Analytical techniques, pharmacokinetics and compatibility}

$(\mathrm{R}, \mathrm{R})$-formoterol and (S, S)-formoterol in human plasma have been analyzed using a sensitive and robust LC-MS-MS method with an Astec chirobiotic T2 column $(250 \times 2.0$ $\mathrm{mm})$. The mobile phase consisted of methanol/acetonitrile/ $\mathrm{H}_{2} \mathrm{O}$ containing $10 \mathrm{mM}$ $\mathrm{NH}_{4} \mathrm{COOH}:$ 78/20/2 (v/v/v) with 0.25 and $0.006 \% \mathrm{CH}_{3} \mathrm{COOH}$ and $\mathrm{NH}_{4} \mathrm{OH}$, respectively. The flow rate was $0.2 \mathrm{~mL} / \mathrm{min}$ and injection volume $30 \mu \mathrm{L}$. The results showed that there was no matrix interference across the elution windows of $(R, R)$-formoterol and $(S, S)$ formoterol. The mean $(n=3)$ correlation coefficients in human plasma were $0.9994 \pm$ 0.0002 and $0.9985 \pm 0.0005$ for $(R, R)$ formoterol and (S, S)-formoterol, respectively. Thus, a validated method has been successfully employed for the quantification of both isomers of formoterol in human plasma. No inversion of $(R, R)$-formoterol to $(\mathrm{S}, \mathrm{S})$-formoterol was observed [20].

The pharmacokinetics of arformoterol tartrate inhalation solution in subjects classified as poor versus extensive Cytochrome P450 (CYP) $2 \mathrm{D} 6$ metabolizers or with reduced uridine diphosphate glycosyltransferase 1 polypeptide A1 (UGT1A1) activity has been characterized. Plasma samples were collected up to $168 \mathrm{~h}$ post-dose and were analyzed by a validated chiral LC/MS/MS method. The results indicated that subjects with reduced CYP2D6 and/or UGT1A1 enzyme activity did not exhibit any increase in systemic exposure to $(R, R)$-formoterol compared with subjects with normal CYP2D6 and/or UGT1A1 enzyme activity [21].

Chemical and physical compatibility of arformoterol (15 $\mu \mathrm{g} / 2 \mathrm{~mL})$ with ipratropium bromide $(0.5 \mathrm{mg} / 2.5 \mathrm{~mL})$, acetylcysteine (800 $\mathrm{mg} / 4 \mathrm{~mL})$, and budesonide $(0.25 \mathrm{mg} / 2 \mathrm{~mL}$ and $0.5 \mathrm{mg} / 2 \mathrm{~mL}$ ) was assessed using visual inspection, $\mathrm{pH}$ measurement and HPLC assay of each active component. The findings indicate that there was no visible signs of change and the $\mathrm{pH}$ of all admixtures ranged from 4.82 to 6.40 , which was within the range of individual drugs. The content of each active component in all the admixtures ranged from 98.3 to $101.4 \%$, compared to the control thus indicating that the acceptance criteria of not more than $10.0 \%$ were met [22].

In another study, human hepatoma cells were cultured in the presence of $(R, R)$-formoterol and $\mathrm{Na}_{2}{ }^{35} \mathrm{SO}_{4}$ to determine whether formoterol is metabolized by sulphate conjugation. The accumulated radiolabeled sulphate conjugates were determined by reversed phase HPLC and scintillation counting of peaks. Mass spectroscopy analysis of individual peaks allowed identification of the fragments of formoterol sulphate. Separation of the constituents of culture medium by reversed phase HPLC produced a major peak with a retention time of $12 \min [10]$.

The levels of $(R, R)$-formoterol and $(S, S)$ formoterol have also been measured using a validated chiral analytical method, in accordance with the United States Food and Drug Administration (USFDA) guidelines. Pharmacokinetic parameters for $(R, R)$ - and $(\mathrm{S}, \mathrm{S})$-formoterol were also determined by non-compartmental methods using WinNonlin Professional 5.1.1 (Pharsight, Mountainview, $\mathrm{CA})$. The results indicate that in vivo chiral inversion did not occur during treatment with arformoterol [16]. In yet another work, a validated chiral HPLC method was successfully applied for the determination of formoterol stereoisomers and their inversion products in an aqueous matrix stored at 5 $70{ }^{\circ} \mathrm{C}$ up to 3 weeks. Analysis was performed on a chiral-AGP column (100 x $4 \mathrm{~mm}, 5 \mu \mathrm{m})$ using a variable mixture of mobile phase at a flow rate of $1.3 \mathrm{~mL} / \mathrm{min}$ and UV detection at $242 \mathrm{~nm}$. All four formoterol stereoisomers were adequately resolved with acceptable detection. The method showed acceptable accuracy (> $88 \%$ ), precision (RSD < $8.5 \%$ ) 
and good linearity $\left(r^{2}>0.9999\right)$ over the concentration range investigated. No significant difference in inversion of the active components in racemic ( $R, R / S, S)$-formoterol fumarate and the single isomer $(R, R)$ arformoterol tartrate drug formulations was observed [23].

Thus, the foregoing indicate that a number of advanced analytical techniques such as chiral HPLC, LC-MS-MS, reversed phase HPLC, etc, can be suitably employed for the quantification of arformoterol tartrate. These methods have not only facilitated the biochemical analysis of the compound but also the determination of its pharmacokinetic and pharmacodynamic parameters, etc.

\section{Dosage}

The recommended dose of arformoterol for patients with COPD is $15 \mu \mathrm{g}$ administered twice daily (morning and evening) by nebulization. It should be administered via a standard jet nebulizer connected to an air compressor. The solution requires no dilution prior to administration [11,12]. However, investigational studies also emphasize that the choice of nebulizer/compressor system can influence the aerosol properties of arformoterol inhalation solution and should be considered when prescribing nebulized medications [24].

\section{Adverse effects}

The adverse effects of arformoterol in patients have been attributed to its activity at $\beta_{2}$ adrenergic receptors, similar to those of other $\beta_{2}$-agonists. Table 2 summarizes the adverse events reported in at least $2 \%$ of patients for arformoterol compared with placebo in clinical trials. These include arrhythmias, atrial tachycardia, pain, chest pain, diarrhea, back pain, sinusitis, rashes, leg cramps and dyspneoa. Some clinical trials also reported other adverse effects such as tremors, insomnia and nervousness [11]. However, the safety profile of arformoterol has been recently documented $[25,26]$.
Table 2: Adverse effects of arformoterol and placebo in clinical trials [12]

\begin{tabular}{lll}
\hline $\begin{array}{l}\text { Adverse } \\
\text { effect }\end{array}$ & $\begin{array}{l}\text { Arformoterol } \\
\mathbf{1 5} \boldsymbol{\mu g} \text { BID } \\
(\%, \mathbf{n = 2 8 8})\end{array}$ & $\begin{array}{l}\text { Placebo } \\
(\%, \mathbf{n = 2 9 3})\end{array}$ \\
\hline $\begin{array}{l}\text { Lung disorders } \\
\text { Peripheral }\end{array}$ & 2 & 1 \\
edema & 3 & 2 \\
Flu syndrome & 3 & 1 \\
Rashes & 4 & 2 \\
Dyspnea & 4 & 2 \\
Leg cramps & 4 & 2 \\
Sinusitis & 5 & 4 \\
Diarrheoa & 6 & 4 \\
Pain & 8 & 5 \\
Chest pain & 7 & 6 \\
Back pain & 6 & 2 \\
\hline
\end{tabular}

\section{Drug interactions and contraindications}

Some findings regarding drug interactions and contraindications of arformoterol are summarized below [12]:

- No pharmacokinetic drug interactions were observed with co-administration of paroxetine, a potent CYP2D6 inhibitor.

- Arformoterol and $\beta$-blockers should generally not be used concomitantly. $\beta$ blockers may interfere with the effects of $\beta$-agonists and produce severe bronchospasm in COPD patients.

- Co-administration with methylxanthines, steroids or diuretics may potentiate the hypokalemia observed with adrenergic agonists.

- Arformoterol should be administered with caution in patients receiving concomitant monoamine oxidase inhibitors, tricyclic antidepressants, or drugs which prolong the QTc interval because of increased adverse cardiovascular effects.

- Arformoterol is contraindicated in patients with a history of hypersensitivity to arformoterol, racemic formoterol or any of the product ingredients. 
- Co-administration with other adrenergic agents by any route should be done with caution because of the potential for sympathomimetic effects.

\section{CONCLUSION}

Bronchodilators hold a central role in the symptomatic management of COPD and asthma. Significant clinical characteristics of arformoterol and current analytical methodologies for its determination have been discussed. Arformoterol has emerged as one of the promising and efficacious drug in bronchospasm and is a selective $\beta_{2}$ adrenergic agonist with long acting bronchodilator activity. Compared to other agents, the pharmacological properties and therapeutic efficacy of this drug appear to be significant. Due to its enhanced clinical efficacy, favourable dosage, pharmacokinetic profile and tolerability, it is an excellent candidate for further investigation of the newer indications of COPD and as an alternative to dry powder inhalers. However, further scientific and technological advancements in pharmacology, clinical studies and analytical techniques are required to optimally harness the therapeutic benefits of the drug as well as its appropriate quality and safety.

\section{ACKNOWLEDGEMENT}

Professor DN Mishra, Dean, Faculty of Pharmaceutical Sciences, Guru Jambheshwar University of Science and Technology, Hisar-125001, India is duly acknowledged for his valuable suggestions during the preparation of this manuscript.

\section{REFERENCES}

1. Reilly JJ, Silverman EK, Shapiro SD. Chronic obstructive pulmonary disease. In: Kasper DL, Braunwald E, Fauci AS, Hauser SL, Longo DL, Jameson JL. (Eds). Harrison's Principles of Internal Medicine. $16^{\text {th }}$ ed. New York: McGrawHill, 2005; pp 1547-1554.

2. Celli BR, MacNee W. Standards for the diagnosis and treatment of patients with COPD: a summary of the ATS/ERS position paper. Eur Respir J 2004; 23: 932-946.

3. Pellegrino $R$, Coletta $G$, Gallo $V$, Brusasco $V$. Structure and function in COPD. Curr_Respir Med Rev 2008; 4: 235-239.

4. Bourdet SV, Williams DM. Chronic obstructive pulmonary disease. In: DiPiro JT, Talbert RL, Yee GC, Matzke GR, Wells BG, Posey LM. (Eds). Pharmacotherapy-A Pathophysiologic Approach. $6^{\text {th }}$ ed. New York: McGraw-Hill, 2005; pp 537-556.

5. Rabe KF, Hurd S, Anzueto A, Barnes PJ, Buist SA, Calverley $P$, Fukuchi $Y$, Jenkins $C$, RodriguezRoisin R, Weel CV, Zielinski J. Global strategy for the diagnosis, management, and prevention of chronic obstructive pulmonary disease. GOLD Executive Summary. Am J Respir Crit Care Med 2007; 176: 532-555.

6. Pauwels RA, Buist AS, Calverley PMA, Jenkins CR, Hurd SS. Global strategy for the diagnosis, management, and prevention of chronic obstructive pulmonary disease. NHLBI/WHO Global initiative for chronic obstructive lung disease. Workshop Summary. Am J Respir Crit Care Med 2001; 163: 1256-1276.

7. Williams DM. Chronic obstructive pulmonary disease. In: Helms RA, Herfindal ET, Quan DJ, Gourley DR. (Eds). Textbook of Therapeutics Drug and Disease Management. $8^{\text {th }}$ ed. Philadelphia: Lippincott Williams and Wilkins, 2006; pp 919-939.

8. Innes JA, Reid PT. Respiratory disease. In: Boon $N A$, Colledge NR, Walker BR, Hunter JAA. (Eds). Davidson's Principles and Practice of Medicine. $20^{\text {th }}$ ed. London: Churchill livingstone, 2006; pp 647-737.

9. Undem BJ. Pharmacotherapy of asthma. In: Brunton LL, Lazo JS, Parker KL. (Eds). Goodman and Gilman's The Pharmacological Basis of Therapeutics. $11^{\text {th }}$ ed. New York: McGraw-Hill, 2006; pp 717-736.

10. Handley $D A$, Senanayake $C H$, Dutczak $W$, Benovic JL, Walle T, Penn RB, Wilkinson HS, Tanoury GJ, Andersson RGG, Johansson F, Morley J. Biological Actions of Formoterol Isomers. Pulm Pharmacol Ther 2002; 15: 135-145.

11. Brovana (arformoterol tartrate Solution) Sepracor Inc., Marlborough, 2006. http://dailymed.nlm.nih.gov/dailymed/archives/f daDrugInfo. .fm?archiveid $=6734$ Accessed 06 Feb 2010.

12. Cada DJ, Levien $T$, Baker DE. Arformoterol Tartrate. Hospital Pharm 2007; 42(5): 447-454.

13. Baumgartner RA, Hanania NA, Calhoun WJ, Sahn SA, Sciarappa K, Hanrahan JP. Nebulized arformoterol in patients with COPD: a 12week, multicenter, randomized, double-blind, double-dummy, placebo- and active-controlled trial. Clin Therap 2007; 29(2): 261-278.

14. Tashkin DP, Donohue JF, Mahler DA, Huang $H$, Goodwin E, Schaefer K, Hanrahan JP, Andrews WT. Effects of arformoterol twice daily, tiotropium once daily, and their 
combination in patients with COPD. Resp Med 2009; 103(4): 516-524.

15. Donohue JF, Hanania NA, Sciarappa K, Grogan $D R$, Baumgartner RA, Hanrahan JP. Abstract from Professional Poster Presentations at AMCP's 2007 Educational Conference. J Manag Care Pharm 2007; 13(8): 697-698.

16. Kharidia J, Fogarty CM, LaForce CF, Maier G, Hsu $R$, Dunnington KM, Curry L, Baumgartner RA, Hanrahan JP. A pharmacokinetic/pharmacodynamic study comparing arformoterol tartrate inhalation solution and racemic formoterol dry powder inhaler in subjects with chronic obstructive pulmonary disease. Pulm Pharmacol Ther 2008; 21: 657-662.

17. Hanrahan JP, Hanania NA, Calhoun WJ, Sahn SA, Sciarappa K, Baumgartner RA. Effect of nebulized arformoterol on airway function in COPD: results from two randomized trials. $J$ COPD 2008; 5(1): 25-34.

18. Hanrahan JP, Grogan DR, Baumgartner RA, Wilson $A$, Cheng $\mathrm{H}$, Zimetbaum PJ, Morganroth J. Arrhythmias in patients with chronic obstructive pulmonary disease (COPD): occurrence frequency and the effect of treatment with the inhaled long-acting beta $_{2}-$ agonists arformoterol and salmeterol. Medicine 2008; 87(6): 319-328.

19. Lotvall J, Palmqvist M, Ankerst J, Persson G, Rosenborg J, Bengtsson T, Rott Z, Poczi M, Devai $A$, and Waldeck $B$. The effect of formoterol over $24 h$ in patients with asthma: the role of enantiomers. Pulm Pharmacol Ther 2005; 18(2): 109-113.

20. Zhou D, Huo M, Hsu R, Maier G, Gu Z. Sensitive and rapid method for the determination of $(R$,
R)-formoterol and (S, S)-formoterol in human plasma using chiral liquid chromatographytandem mass spectrometry. Xenobiotic Laboratories, Inc., AAPS Annual meeting, San Antonio, 2006. http://www.xbl.com/resourceLib/papers_poster .shtml Accessed 07 Feb 2010.

21. Abolin CR, Dunnington S, Hanrahan J, Hsu RS, Kharidia JS, Maier GA, Nguyen LQ. An evaluation of the impact of cytochrome $P 450$ (CYP) 2D6 and UGT1A1 metabolism on the pharmacokinetics of arformoterol tartrate inhalation solution. AAPS Annual Meeting and Exposition, 2007.

22. Bonasia $P$, Cook $C$, Cheng $Y$, Ong S. Compatibility of arformoterol tartrate inhalation solution with three nebulized drugs. Curr Med Res Opin 2007; 23(10): 2477-2483.

23. Akapo S, McCrea C, Gupta J, Roach M, Skinner W. Chiral HPLC analysis of formoterol stereoisomers and thermodynamic study of their interconversion in aqueous pharmaceutical formulations. I Pharmaceut Biomed 2009; 49(3): 632-637.

24. Bauer A, McGlynn P, Bovet LL, Mims PL, Curry LA, Hanrahan J. Output and aerosol properties of 5 nebulizer/compressor systems with arformoterol inhalation solution. Respir Care 2009; 54(10): 1342-1347.

25. King $P$. Role of arformoterol in the management of COPD. Int J COPD 2008; 3(3): 385-391.

26. King P. Pharmacotherapy of chronic obstructive pulmonary disease: focus on arformoterol tartrate. Clin Med: Therap 2009; 1: 1321-1327. 